\title{
Prenatal Smoking Exposure and Neonatal DNA Damage in Relation to Birth Outcomes
}

\author{
HUAI-CHIH TSUI, HONG-DAR ISAAC WU, CHOUH-JIUAN LIN, RUEY-YUN WANG, HSIEN-TSAI CHIU, YANG-CHEN CHENG, \\ TSAN-HUNG CHIU, AND FANG-YANG WU
}

\author{
Institute of Environmental Health [H.-C.T., H.-T.C., Y.-C.C., F.-Y.W.], Departments of Public Health [H.-D.I.W., R.-Y.W.], Nursing \\ [C.-J.L.], and Obstetric and Gynecology [T.-H.C.], China Medical University Hospital, Taichung, 404, Taiwan; Department of Applied \\ Mathematics [H.-D.I.W.], National Chung-Hsing University, Taichung, 402, Taiwan
}

\begin{abstract}
This study investigated whether mothers with prenatal environmental tobacco smoke (ETS) exposure increased the newborn genetic damage and adverse birth outcomes. Study participants were women receiving prenatal care at three hospitals in Central Taiwan and their newborns. Participants were divided into two groups (nonsmokers and ETS-exposed non-smokers) based on maternal ETSexposed status. Comet assay were performed for cord blood samples. Infants born to mothers with prenatal ETS exposure had the highest mean cord blood DNA damage score $(69.7 \pm 42.3)$ and poorer birth outcomes. No negative fetal growth effects appeared among newborns with low DNA damage levels. Among newborns with high DNA damage levels (comet scores $>50$ ), those born to prenatal ETS exposure had an average reduction of $252.7 \mathrm{~g}$ in birth weight, 1.10 $\mathrm{cm}$ shorter in length and a $0.92-\mathrm{cm}$ decrease in head circumference, compared to newborns with no smoking exposure. This study shows that the DNA damage scores can be used as an effect-modifier on the relationships between ETS exposure and adverse birth outcome. The association appears more apparent for the ETS exposure in relation with more severe DNA damage. (Pediatr Res 64: 131-134, 2008)
\end{abstract}

$\mathrm{S}^{\mathrm{t}+\sin }$ tudies have suggested adverse reproductive outcomes among newborns in relation to maternal cigarette smoking and environmental tobacco smoke (ETS) exposure during pregnancy. Most of these studies are based on self-reported smoking status, and serum or urinary cotinine levels as the exposure measures (1-6). Some studies failed to find a significant association (7-11). The discrepancy could be explained by the variability of study populations, sample size, study design, and individual susceptibility $(12,13)$. Other markers linking the association between smoking and/or ETS and pregnant outcomes deserve exploration.

Cigarette smoke contains more than 4000 chemicals (14), including carcinogens such as polycyclic aromatic hydrocarbons (PAHs), arylmines, N-nitrosamines $(15,16)$, and aromatic amines. These compounds can cross the placenta and experimental animal studies have indicated that the fetus and newborn are more susceptible to carcinogens than adults (17-19). A study of white population showed that there is an

\section{Received October 25, 2007; accepted April 1, 2008.}

Correspondence: Fang-Yang Wu, Ph.D., Institute of Environmental Health, China Medical University, No 91, Hsueh-Shih Rd, Taichung 404, Taiwan; e-mail: fywu@mail.cmu.edu.tw

This work was supported by the grants of the Bureau of Health Promotion, Department of Health (BHP-92-Anti-Tobacco-F204), the National Science Council (95-2314-B-039027) and China Medical University (CMU-93-PH-04, CMU94-026, CMU94-079). increased susceptibility to DNA damage from PAHs and the diminished ability to clear ETS components for the fetus (20). de la Chica et al. found that maternal smoking exposure increase structural chromosomal abnormalities and chromosomal lesions in fetus (21). However, the effect of genotoxicity determined by comet assay for infants with prenatal smoking exposure has not been well documented. The comet assay is a sensitive technique allowing the detection of DNA damage at the single cell level. This assay is also effective in detecting DNA damage induced by tobacco smoke toxicants in white blood cells (22).

The smoking prevalence among women in Taiwan has recently increased to $5.95 \%$, and as many as $42.4 \%$ of women are daily exposed to ETS (23). Another studies in Taiwan showed that $58 \%$ of pregnant women and $57 \%$ of neversmoked women in the reproductive age had exposed to ETS either at work or at home $(24,25)$. Our previous investigation indicated that the mean DNA damage level among women with ETS-exposure at work and/or at home was significantly higher than that among non-exposed women $(24,26)$. We hypothesized that the scored comet can be used as the biomarker linking the relationship between the prenatal tobacco smoke exposure and the adverse birth outcomes. This study is the first report using the comet assay to measure neonatal DNA damage and the risk of giving adverse birth outcomes associated with prenatal maternal ETS exposure.

\section{MATERIALS AND METHODS}

Participants, data collection, and sampling. All pregnant women receiving prenatal care between August 2003 and October 2004 at three hospitals in the Central Taiwan were invited to participate in this study. Three hundred eighty-three pregnant women agreed to participate during the third trimester of gestation, and most delivered live singletons. A questionnaire was used to collect information on demographics, smoking status, medical history, and lifestyle habits for each participant. Mothers were divided into three smoking status groups based on their responses to the following questions in the questionnaire: "Have you ever been a smoker?", "Does your spouse smoke?" "Are there any smokers in your household?", and "Can you smell people smoking in your workplace?" A smoker in this study was defined as a mother who currently smoked or had quit smoking after conception. Subjects who had never smoked were assigned to the non-smoker group, and those who did not smoke but were exposed to ETS were assigned to the ETS-exposed group.

Abbreviations: ETS, environmental tobacco smoke; PAHs, polycyclic aromatic hydrocarbons 
However, a total of 24 women were grouped as smokers, excluded because of small sample size.

There were 184 ETS-exposed mothers who had either a smoking partner or could smell people smoking at work. The remaining 175 women were non-smokers. Gestation age (GA) and neonatal birth outcome data (e.g., birth weight, length, head and chest circumference, duration of gestation) were extracted from the medical records. The GA was estimated based on the last menstrual period reported to the physician in all three hospitals.

Blood sampling. Umbilical cord blood samples were obtained from 306 newborns at the deliver. Among them, 93 cord-blood samples had hemolysis phenomenon or had not sufficient volume for the comet assay. Fifteen smokers were excluded because the sample size was too small. In addition to umbilical cord blood specimen, 3-5 mL of whole blood was drawn from each mother. For each umbilical cord, $3 \mathrm{~mL}$ was kept in heparin tubes for the comet assay. All pregnant women gave informed consents to participate in the study and the study was approved by the University Human Subjects Committee.

Comet assay. The comet assay was performed on cord blood samples available for 198 infants born to 104 ETS-exposed participants and 94 non-smokers. Lymphocytes were carefully isolated from the blood using a Histopaque 1077 (Sigma Chemical Co., St. Louis, MO). The buffer coat containing lymphocytes was washed three times with phosphate buffered saline (PBS). Lymphocytes were evaluated for viability before the experiment with trypan blue dye and counted in a Neubauer chamber. Single-cell gel electrophoresis (comet assay) was conducted with the method adapted from $\mathrm{Wu}$ et al. (26) and McNamee et al. (27). The lymphocyte suspension containing about $5 \times 10^{5}$ cells $/ \mathrm{mL}$ was placed on microscopic slides. Cells were stained with $40 \mu \mathrm{L}$ propidium iodide (PI) solution and viewed under a fluorescence microscope (Olympus BX51, Tokyo, Japan), equipped with an excitation filter BP520-550 and a barrier filter BA580-IF, and examined at $\times 100$ magnification. The microscope was connected to a high-sensitivity CCD video camera and a computer with an image analysis system.

The observed extent of DNA damage per cell was calculated by measuring 100 nuclei per participant from two slides. All slides were scored by one reader who was blind to the smoking status of the participants. According to Anderson et al. (28), DNA damage is expressed as a percentage of total fluorescence migrated to the tail in each nucleus (DNA \% in tail), and quantified by visually classifying cells into five categories: no damage $(<5 \%)$, low-level damage (5-20\%), medium-level damage $(20-40 \%)$, high-level damage $(40-95 \%)$, and complete damage $(>95 \%)$. The DNA damage score for each subject was calculated as: (no damage $\times 0)+($ low damage $\times 1)+$ $($ medium damage $\times 2)+($ high damage $\times 3)+($ complete damage $\times 4)$ for each nucleus.

Statistical analyses. Data analyses were performed using SAS statistical software for Windows version 9.1 (SAS institute, Cary, NC). Newborns with gross birth defects and twins were excluded from data analysis. We compared the characteristics of pregnant women and newborns by maternal smoking status (non-smokers and ETS exposed non-smokers). We did not distinguish ETS by spouse from other members because there was no significant difference in mean DNA damage scores between their two types of ETS exposure. Maternal age at the pregnancy, employment, education and drinking, and the newborn sex, gestational age, and body weight, length, head circumference and chest circumference at the birth were compared. The average DNA damage scores obtained from comet assay for cord blood specimens were compared among newborn by maternal ETS-exposed status. The LOESS function (offered by SAS software) identified a specific DNA damage score as the cutoff point for further stratified analysis. Linear regression analysis was used to estimate the fetal growth measures in relationship with maternal ETS-exposed status. This analysis was conducted by stratifying newborns into low and high DNA damage levels using the cutoff score determined by the LOESS function. In the linear regression analyses, maternal age and education, gestational age, employment status, and alcohol drinking were also considered as covariates for adjustment.

\section{RESULTS}

Near half the mothers were exposed to ETS who had higher employment rate and received less education (Table 1). Infants born to never smoking mothers had higher average birth weight than infants of ETS-exposed groups but not significant. There were also no differences in average lengths, head circumferences, and chest circumferences between these two groups of neonates.

Neonates of ETS-exposed mothers had the highest average DNA damage score (69.7) followed by those born to non-
Table 1. Characteristics of mothers and newborns compared by maternal exposure status

\begin{tabular}{lccc}
\hline & & ETS-exposed & \\
& Nonsmoking & nonsmoking & $p^{*}$ \\
\hline Mothers, $n(\%)$ & $175(48.8)$ & $184(51.3)$ & 0.002 \\
Age (y) (SD) & $30.9(4.0)$ & $29.5(4.8)$ & 0.817 \\
BMI (kg/cm ${ }^{2}$ ) (SD) & $21.2(3.0)$ & $21.3(2.9)$ & 0.080 \\
Gestational age (wk) (SD) & $39.1(1.3)$ & $39.4(1.2)$ & \\
Employment, $n$ (\%) & $74(43.0)$ & $48(26.8)$ & 0.001 \\
No & $98(57.0)$ & $131(73.2)$ & \\
Yes & & & \\
Education (y), $n(\%)$ & $5(2.9)$ & $13(7.1)$ & $<0.001$ \\
$<9$ & $109(62.3)$ & $140(76.1)$ & \\
10-12 & $61(34.9)$ & $31(16.9)$ & \\
$>13$ & $171(98.3)$ & $175(96.7)$ & 0.341 \\
Alcohol consumption, $n(\%)$ & $3(1.7)$ & $6(3.3)$ & \\
Never & & & \\
Currently or previously & & & 0.112 \\
Newborns & & & \\
Sex, $n$ (\%) & $84(48.6)$ & $71(40.1)$ & \\
Female & $89(51.5)$ & $106(59.9)$ & \\
Male & $3206.1(405.0)$ & $3172.4(392.2)$ & 0.424 \\
Birth weight (g) (SD) & $51.0(2.0)$ & $50.8(2.2)$ & 0.273 \\
Length (cm) (SD) & $33.5(1.6)$ & $33.5(1.6)$ & 0.768 \\
Head circumference (cm) (SD) & $32.8(1.7)$ & $32.9(1.7)$ & 0.718 \\
Chest circumference (cm) (SD) & & \\
\hline
\end{tabular}

* Comparison of the characteristics of mothers and newborns between non-smoking group and ETS-exposed nonsmoking by $t$-test or $\chi^{2}$ test.

smokers (54.0) (Table 2). The difference between two groups was statistically significant. The LOESS regression analysis showed that the birth weights had a tendency to decrease as the level of DNA damage scores increased. This inverse relationship was even more pronounced when DNA damage scores were greater than 50. The birth lengths increased slightly at first for neonates with DNA damage scores less than 50 and gradually decreased as the DNA damage scores continued to increase. The DNA damage scores had no significant associations with both head and chest circumferences (data not shown).

Based on the LOESS function, we divided neonates into two strata, low-level DNA damage $(\leq 50)$ group and highlevel DNA damage $(>50)$ group, for further linear regression analyses (Table 3). Comparing with non-smoking mothers and ETS-exposed mothers appeared at higher risk of having the adverse fetal growth among their newborns with high-level DNA damage. In the low-level DNA damage stratum, no significant adverse birth effects were found. After adjusting for the covariates in the regression model, the mean birth weights of neonates in the ETS-exposed group was significantly lower than that in the non-smoking group (lowered by $252.7 \mathrm{~g}, p=0.005)$. Neonates in the ETS-exposed group also had a shorter mean body length by $1.10 \mathrm{~cm}(p=0.021)$,

Table 2. Comparison of average cord blood DNA damage score by maternal exposure status

\begin{tabular}{lrrrr}
\hline & \multicolumn{3}{c}{ DNA damage score } & \\
\cline { 2 - 4 } & $\mathrm{n}$ & Mean \pm SD & Range & $p$ \\
\hline Nonsmoking & 94 & $54.0 \pm 33.8$ & $7.02-179.5$ & 0.004 \\
ETS-exposed nonsmokers & 104 & $69.7 \pm 42.3$ & $7.38-181.2$ & \\
\hline
\end{tabular}


Table 3. Regression analysis for fetal growth measures in newborns associated with maternal exposure status stratified by cord blood neonatal DNA damage score

\begin{tabular}{|c|c|c|c|c|c|c|c|c|}
\hline \multirow[b]{2}{*}{ DNA damage score* } & \multirow[b]{2}{*}{$n$} & \multirow[b]{2}{*}{ Mean \pm SD } & \multicolumn{3}{|c|}{ Model $1 \dagger$} & \multicolumn{3}{|c|}{ Model $2 \dagger$} \\
\hline & & & $\beta$ & SE & $\mathrm{p}$ & $\beta$ & SE & $\mathrm{p}$ \\
\hline & \multicolumn{8}{|c|}{ Birth weight $(\mathrm{g})$} \\
\hline \multicolumn{9}{|l|}{ Low-level damage } \\
\hline Non-smoking & 48 & $3144.5 \pm 396.7$ & Referent & - & - & Referent & - & - \\
\hline ETS-exposed non-smokers & 40 & $3147.2 \pm 390.0$ & -0.8 & 86.2 & 0.992 & 78.5 & 91.4 & 0.393 \\
\hline \multicolumn{9}{|l|}{ High-level damage } \\
\hline Non-smoking & 46 & $3275.6 \pm 414.2$ & Referent & - & - & Referent & - & - \\
\hline ETS-exposed non-smokers & 64 & $3108.8 \pm 412.1$ & -166.8 & 79.8 & 0.039 & -252.7 & 87.1 & 0.005 \\
\hline & \multicolumn{8}{|c|}{ Birth length $(\mathrm{cm})$} \\
\hline \multicolumn{9}{|l|}{ Low-level damage } \\
\hline Non-smoking & 48 & $50.8 \pm 1.9$ & Referent & - & - & Referent & - & - \\
\hline ETS-exposed non-smokers & $39^{\mathrm{c}}$ & $50.4 \pm 2.2$ & -0.44 & 0.44 & 0.318 & -0.37 & 0.47 & 0.442 \\
\hline \multicolumn{9}{|l|}{ High-level damage } \\
\hline Non-smoking & 46 & $51.4 \pm 2.0$ & Referent & - & - & Referent & - & - \\
\hline ETS-exposed non-smokers & 64 & $50.5 \pm 2.3$ & -0.95 & 0.42 & 0.025 & -1.10 & 0.47 & 0.021 \\
\hline & \multicolumn{8}{|c|}{ Head circumference $(\mathrm{cm})$} \\
\hline \multicolumn{9}{|l|}{ Low-level damage } \\
\hline Non-smoking & $47^{\mathrm{c}}$ & $33.2 \pm 1.6$ & Referent & - & - & Referent & - & - \\
\hline ETS-exposed non-smokers & 40 & $33.4 \pm 1.8$ & 0.17 & 0.37 & 0.652 & 0.39 & 0.41 & 0.337 \\
\hline \multicolumn{9}{|l|}{ High-level damage } \\
\hline Non-smoking & 46 & $34.0 \pm 1.6$ & Referent & - & - & Referent & - & - \\
\hline ETS-exposed non-smokers & 64 & $33.1 \pm 1.6$ & -0.87 & 0.30 & 0.005 & -0.92 & 0.36 & 0.013 \\
\hline & \multicolumn{8}{|c|}{ Chest circumference $(\mathrm{cm})$} \\
\hline \multicolumn{9}{|l|}{ Low-level damage } \\
\hline Non-smoking & 48 & $32.5 \pm 1.4$ & Referent & - & - & Referent & - & - \\
\hline ETS-exposed non-smokers & 40 & $32.8 \pm 1.8$ & 0.36 & 0.34 & 0.296 & 0.57 & 0.38 & 0.141 \\
\hline \multicolumn{9}{|l|}{ High-level damage } \\
\hline Non-smoking & 46 & $33.1 \pm 1.7$ & Referent & - & - & Referent & - & - \\
\hline ETS-exposed non-smokers & 64 & $32.7 \pm 1.7$ & -0.47 & 0.33 & 0.158 & -0.70 & 0.38 & 0.073 \\
\hline
\end{tabular}

* DNA damage score was divided into low-level $(\leq 50)$ and high-level $(>50)$ damage.

$\dagger$ Model 1 was a simple linear regression; Model 2 adjusted for maternal age, gestational age, BMI, occupation, education level and alcohol consumption.

smaller head circumference by $0.92 \mathrm{~cm}(p=0.013)$, and chest circumference by $0.70 \mathrm{~cm}(p=0.073)$, compared with the nonsmoking group.

\section{DISCUSSION}

Previous studies on the relationship between prenatal smoking status and birth outcomes have focused on newborn birth weight, birth length, and head circumference. Our study found that neonates with the antenatal ETS-exposed group had an average reduction of $33.7 \mathrm{~g}$ in birth weight, compared with non-smoking groups. Although these crude birth weight means were not statistically significant, they agreed with the trend of previous research (29).

After adjusting for potential confounders, our study found that neonates with the antenatal exposure to ETS had an average reduction of $252.7 \mathrm{~g}$ in birth weight, a $1.10 \mathrm{~cm}$ shorter in birth length, and a $0.92 \mathrm{~cm}$ smaller in head circumference, compared with non-smoking groups. In a notable study, Goel et al. found that infants born to mothers exposed to ETS had a mean birth weight of $362 \mathrm{~g}$ less than infants born to non-smoking mothers (30). Lazzaroni et al. have also demonstrated a mean birth weight reduction of $123.7 \mathrm{~g}$ for the infants with antenatal passive smoking exposure. A mean reduction of $51.4 \mathrm{~g}$ in birth weight and a 0.3 -cm decrease in birth length were found in the 11 Italian cities study for ETS exposure; the mean birth head circumference of infants born to non-smoking mothers was found to be $0.1-0.2 \mathrm{~cm}(p<0.10)$ wider than that of both passive smoking and ETS exposures (31).

Research of the harmful effect of ETS-exposed on the fetus using neonatal DNA damage as an indicator is limited. This study is the first using the comet assay to investigate the newborn DNA damage and its relationship to antenatal smoking exposure and birth outcomes. The comet assay is a wellestablished simple technique to determine genotoxicity. It has the advantage of time and effort saving compared with methods to assay sister chromatid exchange SCE and frequency of chromosomal aberrations. This assay has been widely used to detect DNA damage in human lymphocytes caused by tobacco and chemicals. Previous studies revealed that occupational exposure to wood dust, lead, and industrial vinyl chloride monomer increased the DNA damage levels in white blood cells of workers (32-34). Our study used the comet assay to assess the DNA damage levels in umbilical cord blood. The results showed increased DNA damage levels in neonates with antenatal ETS exposure. These results are consistent with the results found by examining SCE or frequency of chromosomal aberrations $(21,35,36)$.

One of the World Trade Center (WTC) disaster studies has examined the birth outcome effect of PAHs adducts in maternal and umbilical blood from non-smoking mothers (37). No significant fetal growth effect of either prenatal ETS exposure or PAH-DNA adducts was found. But PAH-DNA adducts in 
combination with the ETS exposure were associated with decreased newborn birth weight and head circumference. In our study, the fetal growth effects associated with ETS exposure at low DNA damage levels were less impressive. The LOESS function analyses appeared that the prenatal smoking exposure effect became more apparent when the comet scores increased beyond 50. This was why we conducted the multivariate regression analyses by stratifying DNA damage into low-level and high-level using the score of 50 as the cutoff. The low-level DNA damage association resembles the PAHDNA adducts association in the WTC study. The high-level DNA damage association resembles PAH-DNA adducts in combination with the ETS exposure with a greater impact. The negative associations with cigarette smoke exposure become significant at high-level DNA damage, particularly of prenatal ETS exposure with higher DNA damage scores. The newborn weight, length, and head circumference were significantly reduced at higher DNA damage levels. This finding may reflect that the ETS exposure has a greater impact than nonsmoking group on fetus DNA damage. Although, this study was limited with a relatively small sample size and inability to examine other adverse birth outcomes such as fetal growth restriction, preterm birth, low birth weight.

In conclusion, our study found that the DNA damage scores could be used as an effect-modifier on the relationships between ETS exposure and adverse birth outcome. The DNA damage configuration associated with the intake of smoke components could be related to fetal development. This finding warrants additional studies for other types of health effect in addition to reproductive health. The findings in the fetal growth variation associated with the combination of maternal smoking status and DNA damage imply the importance of prenatal ETS exposure prevention.

Acknowledgments. We thank the Taichung Hospital for the assistance in data and specimen collection.

\section{REFERENCES}

1. Abel EL 1980 Smoking during pregnancy: a review of effects on growth and development of offspring. Hum Biol 52:593-625

2. Haddow JE, Knight GJ, Palomaki GE, Kloza EM, Wald NJ 1987 Cigarette consumption and serum cotinine in relation to birthweight. Br J Obstet Gynaecol 94:678-681

3. Eskenazi B, Prehn AW, Christianson RE 1995 Passive and active maternal smoking as measured by serum cotinine: the effect on birthweight. Am J Public Health 85:395-398

4. England LJ, Kendrick JS, Gargiullo PM, Zahniser SC, Hannon WH 2001 Measures of maternal tobacco exposure and infant birth weight at term. Am J Epidemiol 153:954-960

5. Keyler D, Pentel PR, Kuehl G, Collins G, Murphy SE 2003 Effects of nicotine infusion on the metabolism of the tobacco carcinogen 4-(methylnitrosamino)-1-(3pyridyl)-1-butanone (NNK) in rats. Cancer Lett 202:1-9

6. Kharrazi M, DeLorenze GN, Kaufman FL, Eskenazi B, Bernert JT Jr, Graham S, Pearl M, Pirkle J 2004 Environmental tobacco smoke and pregnancy outcome. Epidemiology 15:660-670

7. Koren G 1995 Fetal toxicology of environmental tobacco smoke. Curr Opin Pediatr $7: 128-131$

8. Hauth JC, Hauth J, Drawbaugh RB, Gilstrap LC III, Pierson WP 1984 Passive smoking and thiocyanate concentrations in pregnant women and newborns. Obstet Gynecol 63:519-522
9. MacArthur C, Knox EG 1987 Passive smoking and birthweight. Lancet 1:37-38

10. Zhang J, Ratcliffe JM 1993 Paternal smoking and birthweight in Shanghai. Am J Public Health 83:207-210

11. Fortier I, Marcoux S, Brisson J 1994 Passive smoking during pregnancy and the risk of delivering a small-for-gestational-age infant. Am J Epidemiol 139:294-301

12. Wang X, Zuckerman B, Pearson C, Kaufman G, Chen C, Wang G, Niu T, Wise PH, Bauchner H, Xu X 2002 Maternal cigarette smoking, metabolic gene polymorphism, and infant birth weight. JAMA 287:195-202

13. Hong YC, Lee KH, Son BK, Ha EH, Moon HS, Ha M 2003 Effects of the GSTM1 and GSTT1 polymorphisms on the relationship between maternal exposure to environmental tobacco smoke and neonatal birth weight. J Occup Environ Med 45:492-498

14. Fowles J, Dybing E 2003 Application of toxicological risk assessment principles to the chemical constituents of cigarette smoke. Tob Control 12:424-430

15. Committee on Passive Smoking, National Research Council 1986 Environmental Tobacco Smoke: Measuring Exposures and Assessing Health Effects. Washington, DC: National Academy Press

16. Emmons KM, Abrams DB, Marshall RJ 1992 Exposure to environmental tobacco smoke in naturalistic settings. Am J Public Health 82:24-28

17. Walters MA 1966 The induction of lung tumors by the injection of 9,10-dimethyl1,2-benzanthracene (DMBA) into newborn suckling and young adult mice. A dose response study. Br J Cancer 20:148-160

18. Vesselinovitch SD, Kyriazis AP, Mihailovich N, Rao KV 1975 Conditions modifying development of tumors in mice at various sites by benzo(a)pyrene. Cancer Res 35:2948-2953

19. Rice JM, Ward JM 1982 Age dependence of susceptibility to carcinogenesis in the nervous system. Ann NY Acad Sci 381:274-289

20. Perera FP, Tang D, Tu YH, Cruz LA, Borjas M, Bernert T, Whyatt RM 2004 Biomarkers in maternal and newborn blood indicate heightened fetal susceptibility to procarcinogenic DNA damage. Environ Health Perspect 112:1133-1136

21. de la Chica RA, Ribas I, Giraldo J, Egozcue J, Fuster C 2005 Chromosomal instability in amniocytes from fetuses of mothers who smoke. JAMA 293:1212

22. Ellahuene MF, Perez-Alzola LP, Farfan-Urzua M, Gonzalez-Hormazabal P, Garay M, Olmedo MI, Last JA 2004 Preliminary evaluation of DNA damage related with the smoking habit measured by the comet assay in whole blood cells. Cancer Epidemiol Biomarkers Prev 13:1223-1229

23. DOH 2006 The Tobacco Hazards Control Act. Taipei, Taiwan: Department of Health

24. DOH 2004 The health effects and smoking or ETS exposure during pregnancy. Bureau of Health Promotion, Taipei, Taiwan: Department of Health

25. Wen CP, Levy DT, Cheng TY, Hsu CC, Tsai SP 2005 Smoking behaviour in Taiwan, 2001. Tob Control 14:i51-i55

26. Wu FY, Wu HD, Yang HL, Kuo HW, Ying JC, Lin CJ, Yang CC, Lin LY, Chiu TH, Lai JS 2007 Associations among genetic susceptibility, DNA damage, and pregnancy outcomes of expectant mothers exposed to environmental tobacco smoke. Sci Total Environ. 386:124-133

27. McNamee JP, McLean JR, Ferrarotto CL, Bellier PV 2000 Comet assay: rapid processing of multiple samples. Mutat Res 466:63-69

28. Anderson D, Yu TW, Phillips BJ, Schmezer P 1994 The effect of various antioxidants and other modifying agents on oxygen-radical-generated DNA damage in human lymphocytes in the comet assay. Mutat Res 307:261-271

29. Li CQ, Windsor RA, Perkins L, Goldenberg RL, Lowe JB 1993 The impact on infant birth weight and gestational age of cotinine-validated smoking reduction during pregnancy. JAMA 269:1519-1524

30. Goel P, Radotra A, Singh I, Aggarwal A, Dua D 2004 Effects of passive smoking on outcome in pregnancy. J Postgrad Med 50:12-16

31. Lazzaroni F, Bonassi S, Manniello E, Morcaldi L, Repetto E, Ruocco A, Calvi A, Cotellessa G 1990 Effect of passive smoking during pregnancy on selected perinatal parameters. Int J Epidemiol 19:960-966

32. Palus J, Dziubaltowska E, Rydzynski K 1999 DNA damage detected by the comet assay in the white blood cells of workers in a wooden furniture plant. Mutat Res 444:61-74

33. Danadevi K, Rozati R, Banu BS, Rao PH, Grover P 2003 DNA damage in workers exposed to lead using comet assay. Toxicology 187:183-193

34. Lei Y-C, Yang H-T, Ma Y-C, Huang M-F, Chang WP, Cheng T-J 2004 DNA single strand breaks in peripheral lymphocytes associated with urinary thiodiglycolic acid levels in polyvinyl chloride workers. Mutat Res 561:119-126

35. Shulman LP, Elias S, Tharapel AT, Li LR, Phillips OP, Simpson JL 1991 Sister chromatid exchange frequency in directly prepared cytotrophoblasts: demonstration of in vivo deoxyribonucleic acid damage in pregnant women who smoke cigarettes. Am J Obstet Gynecol 165:1877-1880

36. Pluth JM, Ramsey MJ, Tucker JD 2000 Role of maternal exposures and newborn genotypes on newborn chromosome aberration frequencies. Mutat Res 465:101-111

37. Perera FP, Tang D, Rauh V, Lester K, Tsai WY, Tu YH, Weiss L, Hoepner L, King J, Del Priore G, Lederman SA 2005 Relationships among polycyclic aromatic hydrocarbon-DNA adducts, proximity to the World Trade Center, and effects on fetal growth. Environ Health Perspect 113:1062-1067 